\title{
Correlation between the Inflammation Factors and Intima-Media Thickness in Patients with End-Stage Renal Disease (ESRD) on Regular Hemodialysis
}

\author{
Lestariningsih", Wiguno Projosudjadi², Mochamad Sya'bani ${ }^{3}$, Suharyo Hadisaputro ${ }^{4}$ \\ ${ }^{1}$ Division of Nephrology, Department of Internal Medicine, School of Medicine, Universitas Diponegoro/Dr. Kariadi Teaching \\ Hospital, Semarang, Indonesia \\ ${ }^{2}$ Division of Nephrology, Department of Internal Medicine, Universitas Indonesia, Jakarta, Indonesia \\ ${ }^{3}$ Division of Nephrology, Department of Internal Medicine, Universitas Gadjah Mada, Yogjakarta, Indonesia \\ ${ }^{4}$ Division of Tropic Infection, Department of Internal Medicine, Universitas Diponegoro, Semarang, Indonesia
}

Background: Several emerging problems of regular hemodialysis (HD) including cardiovascular complication or atherosclerosis formation caused by chronic inflammation. High sensitive C-reactive protein (hs-CRP) and intima-media thickness (IMT) of the carotid artery can be applied as atherosclerosis progressivity marker. This study was designed to investigate the relationship between some inflammatory factors, including hs-CRP, interleukin (IL)-6, oxidized-low-density lipoproteins (LDL), with IMT among end-stage renal disease (ESRD) patients. This was the first study in Indonesian population.

Materials and Methods: This cross-sectional study was performed on ESRD patients who performed regular HD at Hemodialysis Unit of Dr. Kariadi Hospital and Telogorejo Hospital Semarang between October 2009 and April 2010. This was a preliminary report for the cohort study.

Results: Seventy-eight HD subjects were enrolled in this study, with mean age of 49.8 years old. Mean HD duration was 25.5 \pm 32.16 months. The mean carotid artery wall thickness was $0.64 \pm 0.149 \mathrm{~mm}$. IL-6, hs-CRP, and ox-LDL level were higher in IMT group $\geq 0.5 \mathrm{~mm}$ than IMT group $<0.5 \mathrm{~mm}$. There was a significant correlation between hs-CRP (prevalence ratio $(P R)=1.3 ; 95 \%$ confidence interval $(\mathrm{Cl})=1.02-1.7$; $p$-value=0.01) as well as IL-6 $(\mathrm{PR}=1.5 ; 95 \% \mathrm{Cl}=1.1-2.0 ; p$-value<0.001) and IMT wall thickness. The oxidized-LDL level was not a significant factor to be associated with IMT. The cut-off value for hsCRP and IL-6 to predict IMT progressivity was $2.8 \mathrm{mg} / \mathrm{L}$ and $2.88 \mathrm{mg} / \mathrm{L}$, respectively.

Conclusion: There was a significant correlation between IL- 6 and hs-CRP levels and IMT. There was not significant correlation between oxidized LDL and IMT.

Keywords: hemodialysis, atherosclerosis, IMT, IL-6, hs-CRP, Oxidized-LDL

Date of submission: December 24, 2018

Last Revised: January 29, 2019

Accepted for publication: January 30, 2019

Corresponding Author:

Lestariningsih

Child Division of Nephrology, Department of Internal Medicine

School of Medicine, Universitas Diponegoro/ Dr. Kariadi Teaching Hospital

Jl. Prof. H. Soedarto, Tembalang, Semarang

E-mail: petrisemarang@yahoo.com

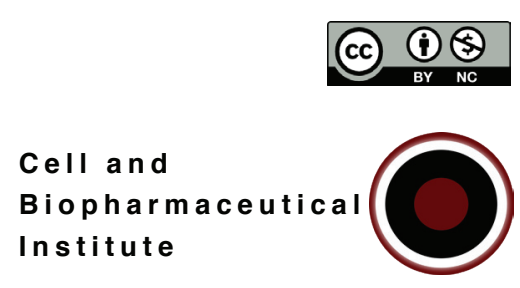




\section{Introduction}

As of December 31, 2015, $\sim 0.7$ million patients were being treated for end-stage renal disease (ESRD) in the United States. ${ }^{1}$ Hemodialysis (HD) might causes new problems such as cardiovascular complications, as the result of chronic inflammation on dialysis. ${ }^{2}$ Clinical manifestation of cardiovascular complication includes atherosclerosis, arteriosclerosis and cardiomyopathy. Cardiovascular risk factors are traditional risk factors (TRF), uremic-related risk factors (URFR) and other factors related to hemodialysis. ${ }^{3}$

There are three main processes related to inflammation and atherosclerosis progression, such as reactive oxygen species (ROS), interleukin (IL)-6, and high sensitive C-reactive protein (hs-CRP) synthesis, and vascular injury. ${ }^{4,5}$ Oxidized-low-density lipoproteins (ox-LDL), one of the oxidative stress markers and inflammation biomarkers are pro-atherogenic. ${ }^{6,7}$ Chronic inflammation on HD increase lipoprotein phospholipid oxidation in the form of ox-LDL. Macrophages catch ox-LDL, thus induce IL-6 synthesis. ${ }^{8}$ The processes are chronic persistent and lead to endothelial dysfunction.

Inflammation exposure in HD is supposedly due to the type of atherosclerosis progression. ${ }^{9}$ It may be defined by the intimal-medial thickness (IMT) serial examination. Carotid IMT study and endothelial adhesion molecules in the foreign general population reported that risk of myocardial infarction increased in IMT value $>0.82 \mathrm{~mm}$ $(0.82-1.2 \mathrm{~mm})^{10}$ Mannheim Consensus on carotid IMT in 2004, IMT value based on age and cardiovascular risk factors, from Framingham risk factors, IMT mean 0.63-0.84 $\mathrm{mm} .{ }^{11,12}$ IMT normal value in normal population reported on Salonen study rates $<0.5-0.65 \mathrm{~mm}$ in 50 years old age with the increased of IMT rates up to $0.008 \mathrm{~mm} /$ years. ${ }^{13}$ Study of atherosclerosis risk in the community (ARIC) reported in hypertension population, IMT value increase $0.01 \mathrm{~mm} /$ year. ${ }^{14,15}$ Carotid IMT and endothelial adhesion molecule foreign study reported myocardial infarction risk increased on IMT value $>0.82 \mathrm{~mm}(0.82-1.2 \mathrm{~mm}) .^{16,17}$ This is the first study from Central Java Region, Indonesia.

\section{Materials and methods}

This cross-sectional study was done on the subjects who received regular HD on Hemodialysis Unit of Dr. Kariadi General Hospital and Telogorejo Hospital Semarang from
October 2009 to April 2010. The study was approved by the Ethical Committee of the Faculty of Medicine, Diponegoro University/Dr. Kariadi Hospital (No. 66/EC/ FK/RSDK/2010) and was conducted in accordance with the Declaration of Helsinki. All subjects were given information regarding this study and signed the informed consent.

Blood samples were collected after an 8 hours overnight fast. The blood collected before dialysis for amount $20 \mathrm{~mL}$ and keep into ethylenediaminetetraacetic acid (EDTA) tube. Complete blood count was measured by flow cytometry method (Cell-Dyn Saphire, Abbott Diagnostics Division, Santa Clara, USA), plasma cholesterol, plasma triglyceride, serum calcium, phosphate, and plasma albumin was measured by homogenous enzymatic colorimetric assay (Dade Behring, Siemens, German).

IL-6 level was measured using the human IL-6 immunoassay method (Quantikine ${ }^{\circledR}$ HS Elisa kit, R\&D Systems, Minneapolis, USA). Plasma levels of hs-CRP were measured by the particle-enhanced immunoturbidimetric method (TMS, Tokyo Boeki Machinery LTD, Tokyo, Japan). Serum creatinine (Cr), uric acid (UA), high density lipoprotein (HDL), LDL, lactate dehydrogenase (LDH), blood glucose (BG), HbA1C, ox-LDL was measured by enzymatic method (TMS, Tokyo Boeki Machinery LTD, Tokyo, Japan). Homocystein were measured by immunoassay method (IMX immunology analyzer, Ensefal Medica Prima, Jakarta, Indonesia). We used laboratory of Dr. Kariadi Hospital, Biochemistry Laboratory of Gajah Mada and Prodia Clinical Laboratory. IMT was measured at carotid arteries by B-mode USG (LOGIQ Ultrasound system, GE Healthcare P6, year 2010, type 55011) at Department of Radiology, Dr. Kariadi Hospital Semarang. Measurement of IMT was done by a Radiologist. Blood pressure was classified according to $7^{\text {th }}$ Joint National Committee (JNC) on Prevention, Detection, Evaluation, and Treatment of High Blood Pressure.

Correlation between levels of hs-CRP with IMT were analyzed with Chi-Square. Correlation levels of IL-6, oxLDL with IMT analyzed with Fisher Exact test. Two-sided $p \leq 0.05$ was considered as statistically significant. These data was analysed used SPSS ver 19 (SPSS Inc., Chicago, Illinois, United States.

\section{Results}

Most of the subject has normal glucose, HbA1C and cholesterol levels. Most of the subject has low LDH level, 
high triglyceride and high homocysteine levels. The subjects with IMT $>0.5 \mathrm{~mm}$ were older than $\mathrm{IMT} \leq 0.5 \mathrm{~mm}(p=0.03)$. The level of HDL is lower in the subject with thickening of carotid artery than no thickening (31. 3 vs. 37.0, $p=0.02$ ) (Table 1).

Table 2 showed that according to the mean of the right and left IMT of the study, the majority (83.3\%) of the subjects have carotid artery wall thickness of more than 0.5 $\mathrm{mm}$. This indicates a wall thickening of carotid artery has been noted in more than $80 \%$ of patients with regular HD in this study population.

Levels of IL-6 are higher in the subjects with IMT $>0.5 \mathrm{~mm}$ than subject with IMT $<0.5 \mathrm{~mm}$ (10.3 vs. 2.7, $p=0.001$ ). Levels of ox-LDL are higher in the subjects with IMT $>0.5 \mathrm{~mm}$ than subject with IMT $<0.5 \mathrm{~mm}(102,657.5$ vs. 66,714.4, $p=0.03$ ). Levels of hs-CRP are higher in the subjects with IMT $>0.5 \mathrm{~mm}$ than subject with IMT $<0.5 \mathrm{~mm}$ (10.1 vs. 3.0, $p=0.003$ ) (Table 3).

Table 4 showed the trend of thickening IMT and risk of cardiovascular disease according to levels of hs-CRP.
The trend of thickening carotid artery linear to the risk of cardiovascular disease. The group with IMT $0.5 \mathrm{~mm}$ have a high risk of cardiovascular disease. This result is significant statistically (X2, $p=0,004)$.

There is a correlation between hs-CRP levels and IMT (prevalence ratio $(\mathrm{PR})=1.3 ; 95 \%$ confidence interval $(C I)=1.02-1.7 ; p=0.01)$. Table 5 showed that subject with hs-CRP levels $>2.8 \mathrm{mg} / \mathrm{L}$ have the risk of 1.3 progress to thickening of the carotid artery. The sensitivity and specificity are $67.7 \%$ and $69.2 \%$, respectively. The positive predictive value (PPV) is $30.0 \%$ and accuracy $67.9 \%$. There are correlation between IL-6 levels and IMT ( $\mathrm{PR}=1.5 ; 95 \%$ $\mathrm{CI}=1.1-2.0 ; p<0.001)$.

The subject with IL-6 levels $>2.9 \mathrm{mg} / \mathrm{L}$ has risk 1.5 times to progress to thickening of the carotid artery. The sensitivity and specificity are $73.8 \%$ and $76.9 \%$, respectively. PPV and negative predictive value (NPV) are $94.5 \%$ and $37.0 \%$, respectively. There was not significant correlation between ox-LDL levels and IMT (PR=1.2; 95\% CI $0.9-1.6 ; p=0.1)$.

Table 1. Baseline characteristics of subjects according to IMT category $(n=78)$.

\begin{tabular}{|c|c|c|c|}
\hline \multirow[b]{2}{*}{ Variables } & \multicolumn{2}{|c|}{ IMT Catagory } & \multirow[b]{2}{*}{$p$} \\
\hline & $\begin{array}{c}>0.5 \mathrm{~mm} \\
(\mathrm{n}=65)\end{array}$ & $\begin{array}{l}\leq 0.05 \\
(n=13)\end{array}$ & \\
\hline Age (year), mean $\pm \mathrm{SD}$ & $51.3 \pm 9.69$ & $42.0 \pm 11.18$ & 0.03 \\
\hline Sex, n $(\%)$ & & & 0.7 \\
\hline Male & $49(62.8)$ & $9(11.5)$ & \\
\hline Female & $16(20.5)$ & $4(5.1)$ & \\
\hline Diabetes history, $\mathrm{n}(\%)$ & & & 0.5 \\
\hline Present & $11(14.1)$ & $2(2.6)$ & \\
\hline Absent & $52(66.6)$ & $11(14.1)$ & \\
\hline Blood pressure status, $\mathrm{n}(\%)$ & & & 0.4 \\
\hline Normal $(<120 / 80 \mathrm{mmHg})$ & $6(7.7)$ & $0(0.0)$ & \\
\hline Borderline $(120 / 80-139 / 89 \mathrm{mmHg})$ & $15(19.2)$ & $2(2.6)$ & \\
\hline Hypertension (> 140/90 mmHg) & $44(56.4)$ & $11(14.1)$ & \\
\hline Blood glucose $(\mathrm{mg} / \mathrm{dL})$, mean $\pm \mathrm{SD}$ & $134.4 \pm 87.93$ & $103.9 \pm 24.39$ & 0.4 \\
\hline $\mathrm{HbA} 1 \mathrm{C}(\%)$, mean $\pm \mathrm{SD}$ & $6.0 \pm 1.66$ & $5.4 \pm 0.55$ & 0.3 \\
\hline Total cholesterol $(\mathrm{mg} / \mathrm{dL})$, mean $\pm \mathrm{SD}$ & $144.0 \pm 32.27$ & $143.6 \pm 27.57$ & 0.9 \\
\hline Triglyceride $(\mathrm{mg} / \mathrm{dL})$, mean $\pm \mathrm{SD}$ & $124.5 \pm 64.51$ & $119.7 \pm 46.65$ & 0.9 \\
\hline $\mathrm{HDL}(\mathrm{mg} / \mathrm{dL})$, mean $\pm \mathrm{SD}$ & $31.3 \pm 10.23$ & $37.0 \pm 8.03$ & 0.02 \\
\hline Uric acid $(\mathrm{mg} / \mathrm{dL})$, mean $\pm \mathrm{SD}$ & $7.9 \pm 2.43$ & $8.0 \pm 2.10$ & 0.8 \\
\hline Phosphate $(\mathrm{mmol} / \mathrm{L})$, mean $\pm \mathrm{SD}$ & $5.9 \pm 2.11$ & $5.5 \pm 1.69$ & 0.7 \\
\hline Calcium $(\mathrm{mmol} / \mathrm{L})$, mean $\pm \mathrm{SD}$ & $8.8 \pm 0.73$ & $8.6 \pm 0.51$ & 0.5 \\
\hline Homocysteine $(\mu \mathrm{mol} / \mathrm{L})$, mean $\pm \mathrm{SD}$ & $25.9 \pm 9.66$ & $25.8 \pm 6.98$ & 0.6 \\
\hline
\end{tabular}


Table 2. Carotid artery IMT examination, by B-mode Doppler ultrasound.

\begin{tabular}{lcc}
\multicolumn{1}{c}{ Wall thickness } & Mean \pm SD & $\begin{array}{c}\text { Proportions } \\
\mathbf{n}(\%)\end{array}$ \\
\hline Right carotid artery (mm) & $0.65 \pm 0.188$ & - \\
Left carotid artery (mm) & $0.63 \pm 0.150$ & \\
Mean carotid artery wall thickness (mm) & $0.64 \pm 0.149$ & \\
Left carotid artery examination & & \\
$>0.5 \mathrm{~mm}$ & - & $61(78.2)$ \\
$\leq 0.5 \mathrm{~mm}$ & - & $17(21.8)$ \\
Right carotid artery examination & - & $65(83.3)$ \\
$>0.5 \mathrm{~mm}$ & - & $13(16.7)$ \\
$\leq 0.5 \mathrm{~mm}$ & & \\
\hline
\end{tabular}

Note: According to mean carotid artery wall thicknes.

\section{Discussion}

The majority of subjects in this study have sustained carotid IMT thickening. This result was similar to the Salonen, reporting that the higher the age, thus the thicker the IMT. ${ }^{13}$ There was a similar study by Kawamoto, et al., in Japan, which reported the interaction between IMT and subendothelial plaque, and diabetes mellitus with a high level of CRP. ${ }^{18}$ In Kawamoto study, the plaque was included on IMT thickness, but in this study, IMT was examined in the area that free of plaque. This might give a different result on the interaction of diabetes mellitus and IMT on both studies.

This study showed hs-CRP could be an indicator of IMT thickening, and Kawamoto did not analyze this. The subjects with thick IMT had the IL-6 level higher than subjects with no thick IMT and IL-6 analysis could be an indicator of IMT thickness. A cross-sectional study by Kato, et al., reported a high level of IL-6 in hemodialysis patients who had atherosclerosis compared to the healthy subject. ${ }^{19}$ Subjects with thick IMT majority had ox-LDL level higher than non-thick IMT subject, but in this study ox-LDL could not be an indicator of IMT. Another study also reported the correlation between ox-LDL and anti-oxLDL with IMT, neither ox-LDL nor anti-ox-LDL has any correlation with cardiovascular mortality in hemodialysis population, but there was a correlation between ox-LDL and anti-ox-LDL with cardiovascular mortality in general population. ${ }^{20}$ The difference was explained that in chronic, there was a considerable hemodialysis-accumulated uremic toxin substances that activated ox-LDL and anti-ox-LDL formation.

Carotid IMT testing is a safe, noninvasive and cost effective method to detect early atherosclerotic vascular diseases. ${ }^{21}$ Cardiovascular disease is still the main cause of death $(50 \%)$ in ESRD patients with hemodialysis where the non-traditional risk factors (oxidative stress, uremia, overload, renin-angiotensin system, uremic toxin, proinflammatory cytokines) play a greater role in changes in vascular homeostasis and atherosclerosis. ${ }^{22-24}$ Changes in the structure of the carotid artery can be a window of change in the structure of the coronary arteries. The common IMT

Table 3. Pro-inflammatory factors of the subject according to the IMT.

\begin{tabular}{|c|c|c|c|}
\hline \multirow[b]{2}{*}{ Variables } & \multicolumn{2}{|c|}{ IMT } & \multirow[b]{2}{*}{$p^{*}$} \\
\hline & $\begin{array}{c}>0.5 \mathrm{~mm} \\
(\mathrm{Mean} \pm \mathrm{SD})\end{array}$ & $\begin{array}{c}\leq 0.5 \mathrm{~mm} \\
(\mathrm{Mean} \pm \mathrm{SD})\end{array}$ & \\
\hline IL-6 (pg/mL) & $10.3 \pm 12.6$ & $2.7 \pm 2.16$ & 0.001 \\
\hline Ox-LDL (ng/mL) & $102,657.5 \pm 90,844.3$ & $66,714.4 \pm 24,866.9$ & 0.03 \\
\hline hs-CRP (mg/L) & $10.1 \pm 12.5$ & $3.0 \pm 3.5$ & 0.003 \\
\hline
\end{tabular}

*Mann-Whitney test; SD: standard deviation. 
Table 4. Correlation between the thickening of carotid artery and hs-CRP level $(n=78)$.

\begin{tabular}{lccc}
\hline \multirow{2}{*}{ Level of hs-CRP } & \multicolumn{2}{c}{ IMT Category } & \multirow{2}{*}{ Total } \\
\cline { 2 - 3 } & $\begin{array}{c}>\mathbf{0 . 5} \\
(\mathbf{n = 6 5})\end{array}$ & $\begin{array}{c}\leq \mathbf{0 . 5 5} \\
(\mathbf{n}=\mathbf{1 3})\end{array}$ & \\
\hline Low risk $(<1 \mathrm{mg} / \mathrm{L})$ & $9(11.5 \%)$ & $7(9.0 \%)$ & $16(20.5 \%)$ \\
Average risk $(1-3 \mathrm{mg} / \mathrm{L})$ & $13(16.7 \%)$ & $2(2.6 \%)$ & $15(19.2 \%)$ \\
High risk $(>3 \mathrm{mg} / \mathrm{L})$ & $43(55.1 \%)$ & $4(5.1 \%)$ & $47(60.3 \%)$ \\
Total & & $13(16.7 \%)$ & $78(100 \%)$ \\
\hline
\end{tabular}

$\mathrm{X} 2$ test; $p=0.004$; According to AHA/CDC recommendation.

examination was correlated with coronary atherosclerosis. ${ }^{25}$ Early identification of IMT must be done in order to prevent increased morbidity and mortality of cardiovascular disease or atherosclerosis progression.

Vascular complications in the HD subjects of is mainly driven by inflammatory factors and overexpression of oxidative stress-that activated by exposure to hemodialysis and the effects of uremia. This vascular damage is influenced by advanced glycation end product (AGE-s) which accumulates in the serum and tissue of ESRD hemodialysis patients. High levels of AGE-s in the ESRD patients with hemodialysis are not affected by diabetes or non-diabetic status. $^{26,27}$

Szeto, et al., reported in the Chinese population also reported the same result with a lower incidence rate of carotid artery IMT thickness $(59.6 \%) .{ }^{13}$ This difference in incidence is probably due to differences in the degree of CKD in the research subjects used. In this study, the research subjects were ESRD patients while in Szeto's study the subjects of the study were CKD patient with stage 3 and $4 .{ }^{13}$

\section{Conclusion}

There is a correlation between IL-6 and hs-CRP and IMT, thus it can be used as an indicator of IMT on ESRD-regular HD. There is not significant correlation between oxidized LDL and IMT.

The hs-CRP level can be examined periodically on ESRD patients to detect early atherosclerosis complications in Hemodialysis Unit, also to improve the life expectancy of ESRD patients. Further studies should be done to follow up the progressive IMT on regular hemodialysis ESRD patients and to prevent progressive IMT.

Table 5. Correlation between the levels of hs-CRP, IL-6, ox-LDL with IMT thickness $(n=78)$.

\begin{tabular}{|c|c|c|c|c|}
\hline & \multicolumn{2}{|c|}{ IMT category } & \multirow[b]{2}{*}{$p$} & \multirow{2}{*}{$\begin{array}{c}\text { Prevalence } \\
\text { Ratio } \\
\text { (95\% CI) }\end{array}$} \\
\hline & $\begin{array}{c}>0.5 \mathrm{~mm} \\
(\mathrm{n}=65)\end{array}$ & $\begin{array}{c}\leq 0.5 \mathrm{~mm} \\
(\mathrm{n}=13)\end{array}$ & & \\
\hline Levels of hs-CRD & & & $0.01^{\mathrm{a}}$ & $1.3(1.02-1.7)$ \\
\hline$>2.8(\mathrm{mg} / \mathrm{L})$ & $44(56.4 \%)$ & $4(5.1 \%)$ & & \\
\hline$\leq 2.8(\mathrm{mg} / \mathrm{L})$ & $21(26.9 \%)$ & $9(11.5 \%)$ & & \\
\hline Levels of IL-6 & & & $<0.001^{\mathrm{b}}$ & $1.5(1.1-2.0)$ \\
\hline$>2.9(\mathrm{pg} / \mathrm{mL})$ & $48(61.5 \%)$ & $3(3.8 \%)$ & & \\
\hline$\leq 2.9(\mathrm{pg} / \mathrm{mL})$ & $17(21.8 \%)$ & $10(12.8 \%)$ & & \\
\hline Levels of ox-LDL & & & $0.1^{\mathrm{b}}$ & $1.2(0.9-1.6)$ \\
\hline$>73.75(\mathrm{ng} / \mathrm{mL})$ & $47(60.3 \%)$ & $6(7.7 \%)$ & & \\
\hline$\leq 73.75(\mathrm{ng} / \mathrm{mL})$ & $18(23.1 \%)$ & $7(9.0 \%)$ & & \\
\hline
\end{tabular}

${ }^{a}$ Chi-square test; ${ }^{b}$ Fisher exact test; The cut-off value of hs-CRP, IL-6, ox-LDL were 2.8, $2.9,74.5$ respectively. These value were calculated by ROC. 


\section{Acknowledgment}

Sincere thanks to Directors of Dr. Kariadi Hospital and Telogerejo Hospital for their support in the patient's management. Thanks to the patients that participated this study.

\section{References}

1. Collins AJ, Foley RN, Gilbertson DT, Chen S. United States Renal Data System public health surveillance of chronic kidney disease and end-stage renal disease. Kidney Int Suppl. 2015; 5(1): 2-7.

2. Stenvinkel P. Inflammation in end-stage renal failure: could it be treated? Nephrol Dial Transpl. 2002; Suppl 8: 33-8.

3. Bowry S, Kuchienke KU, Ronco C. The cardiovascular burden of the dialysis patient: the impact of dialysis technology. In: Ronco C, Brendolan A, Levin NW, editors. Cardiovascular Disorders in Hemodialysis. Basel: Karger; 2005. p.230-9.

4. Heidari B. C-reactive protein and other markers of inflammation in hemodialysis patients. Caspian J Intern Med. 2013; 4(1): 611-6.

5. Park KA, Jo HM, Han JS, Kim MJ, Kwun DH, Park MY, et al. Features of atherosclerosis in hemodialysis patients. Kidney Res. 2013; 32(4): 177-82.

6. Smook MLF, Leeuwen $M$ van, Heeringa P, Damoiseaux JGMC, Theunissen R, Daemen MJAP, et al. Anti-oxLDL antibody isotype levels, as potential markers for progressive atherosclerosis in APOE-/- and APOE-/-CD40L-/- mice. Clin Exp Immunol. 2008; 154(2): 264-9.

7. Raghavamenon SPA, Garelnabi MO, Santanam N. Oxidized LowDensity Lipoprotein. Methods Mol Biol. 2010; 610: 403-17.

8. Taheri S, Baradaran A, Aliakbarian M, Mortazavi M. Level of inflammatory factors in chronic hemodialysis patients with and without cardiovascular disease. J Res Med Sci. 2017; 22: 47. doi: 10.4103/jrms.JRMS 28215.

9. Santoro A. Cardiac effect of chronic inflammation in dialysis patient. Nephrol Dial Transpl. 2002; 175(8): 10-5.

10. Szeto C, Chow K, Woo K, Chook P, Ha-Kwan B. Carotid intima media thickness predicts cardiovascular diseases in Chinese predialysis patients with chronic kidney disease. J Am Soc Nephrol. 2007; 18(6): 1966-72

11. Touboul P, Hennerici M, Meairs S, Adams H, Amarenco P, Desvarieux M. Mannheim intima-media thickness consensus. Cerebrovasc Dis. 2004; 18(4): 346-9.

12. Eigenbrodt M, Bursac Z, Couper. Mathematical estimation of the potential effect of vascular remodeling/dilatation on B-mode ultrasound intima-medial thickness. Q J Med. 2004; 97(11): 729-37.

13. Salonen JT, Salonen R. Ultrasonographically assessed carotid morphology and the risk of coronary heart disease. Arterioscler Thromb. 1991; 11(5): 1245-9.

14. Liao D, Arnett D, Tyroler H, Riley W, Chambless L, Szklo M, et al. Arterial stiffness and the development of hypertension. The ARIC study. Hypertension. 1999; 34(2): 201-6.

15. Kaess BM, Larson MG, Hamburg NM, Vita JA, Levy D, Benjamin EJ, et al. Aortic stiffness, blood pressure progression, and incident hypertension and Incident Hypertension. 2012; 308(9): 875-81.

16. Adolphe A, Cook LS, Huang X. A Cross-sectional study of intimamedia thickness, ethnicity, metabolic syndrome, and cardiovascular risk in 2268 study participants. Mayo Clin Proc. 2009; 84(3): 221-8.

17. Mackinnon A, Dunne P, Sitzer M, Buehler A, Kegler S, Markus H. Rate and determinants of site-specific progression of carotid artery intima-media thickness. Stroke. 2004; 35(9): 2150-4.

18. Kawamoto R, Tomita H, Inoue A, Ohtsuka N, Kamitani A. Impact of C-reactive protein on the likelihood of carotid atherosclerosis in Japanese adults. J Atheroscler Thromb. 2006; 13(4): 175-82.

19. Kato A, Odamaki M, Takita T, Maruyama Y, Kumagai H, Hishida A. Association between interleukin- 6 and carotid atherosclerosis in hemodialysis patients. Kidney Int. 2002; 61(3): 1143-52.

20. Ok E, Kircelli F, Asci G, Altunel E, Ertilav M. Neither oxidized nor anti- oxidized low-density lipoprotein level is associated with atherosclerosis or mortality in hemodialysis patients. Hemodial Int. 2012; 16(3): 334-41.

21. Kasliwal RR, Bansal M, Devang D, Sharma M. Carotid intima-media thickness: current evidence, practices, and Indian experience. Indian J Endocrinol Metab. 2014; 18(1): 13-22.

22. Piroddi M1, Depunzio I, Calabrese V, Mancuso C, Aisa CM, Binaglia $\mathrm{L}$, et al. Oxidatively-modified and glycated proteins as candidate pro-inflammatory toxins in uremia and dialysis patients. Amino Acids. 2007; 32(4): 573-92.

23. Kharbanda R, MacAllister R. The atherosclerosis time-line and the role of the endothelium. Curr Med Chem - Immunol Endocr Metab Agents. 2005; 1(1): 47-52.

24. Stary HC. Natural history and histological classification of atherosclerotic lesions. Arter Thromb Vasc Biol. 2000; 20(5): $1177-8$.

25. Sonoda M, Yonekura K, Yokoyama I, Takenaka K, Nagai R, Aoyagi T. Common carotid intima-media thickness is correlated with myocardial flow reserve in patients with coronary artery disease: a useful non-invasive indicator of coronary atherosclerosis. Int J Cardiol. 2004; 93(2-3): 131-6.

26. Schwedler, S, Schinzel, R. Vaith, P. Wanner C. Inflammation and advanced glycation end products in uremia: simple coexistence, potentiation or causal relationship? Kidney Int Suppl. 2001; 78: S32-6.

27. Kalousová, M. Zima, T. Tesar, V. Lachmanová J. Advanced glycation end products and advanced oxidation protein products in hemodialyzed patients. Blood Purif. 2002; 20(6): 531-6. 